\title{
Combined CUTLASS, EISCAT and ESR observations of ionospheric plasma flows at the onset of an isolated substorm
}

\author{
T. K. Yeoman, J. A. Davies, N. M. Wade, G. Provan, S. E. Milan \\ Department of Physics and Astronomy, University of Leicester, University Road, Leicester, LE1 7RH, UK
}

Received: 24 January 2000 / Revised 12 May 2000 / Accepted: 16 May 2000

\begin{abstract}
On August 21st 1998, a sharp southward turning of the IMF, following on from a $20 \mathrm{~h}$ period of northward directed magnetic field, resulted in an isolated substorm over northern Scandinavia and Svalbard. A combination of high time resolution and large spatial scale measurements from an array of coherent scatter and incoherent scatter ionospheric radars, ground magnetometers and the Polar UVI imager has allowed the electrodynamics of the impulsive substorm electrojet region during its first few minutes of evolution at the expansion phase onset to be studied in great detail. At the expansion phase onset the substorm onset region is characterised by a strong enhancement of the electron temperature and UV aurora. This poleward expanding auroral structure moves initially at $0.9 \mathrm{~km} \mathrm{~s}^{-1}$ poleward, finally reaching a latitude of $72.5^{\circ}$. The optical signature expands rapidly westwards at $\sim 6 \mathrm{~km} \mathrm{~s}^{-1}$, whilst the eastward edge also expands eastward at $\sim 0.6 \mathrm{~km} \mathrm{~s}^{-1}$. Typical flows of $600 \mathrm{~m} \mathrm{~s}^{-1}$ and conductances of $2 \mathrm{~S}$ were measured before the auroral activation, which rapidly changed to $\sim 100 \mathrm{~m} \mathrm{~s}^{-1}$ and 10-20 S respectively at activation. The initial flow response to the substorm expansion phase onset is a flow suppression, observed up to some $300 \mathrm{~km}$ poleward of the initial region of auroral luminosity, imposed over a time scale of less than $10 \mathrm{~s}$. The high conductivity region of the electrojet acts as an obstacle to the flow, resulting in a region of low-electric field, but also low conductivity poleward of the high-conductivity region. Rapid flows are observed at the edge of the high-conductivity region, and subsequently the high flow region develops, flowing around the expanding auroral feature in a direction determined by the flow pattern prevailing before the substorm intensification. The enhanced electron temperatures associated with the substorm-disturbed region extended some $2^{\circ}$ further poleward than the UV auroral signature associated with it.
\end{abstract}

Correspondence to: T. K. Yeoman

e-mail: yxo@ion.le.ac.uk
Key words: Ionosphere (auroral ionosphere) Magnetospheric physics (magnetosphere - ionosphere interactions; storms and substorms)

\section{Introduction}

The ionospheric electrojets during the substorm expansion phase are known to have a highly time-dependent electric field and conductivity structure, as a consequence of the fields and particle precipitation imposed on the nightside ionosphere by the Earth's magnetotail. These ionospheric electric field and conductivity changes combine to produce the characteristic ground magnetic perturbations during the substorm expansion phase. VHF coherent scatter radars were first used to study the spatial structure of the substorm electric fields (Baumjohann et al., 1981; Inhester et al., 1981; Opgenoorth et al., 1983) and suggested a region of low-electric field within the dynamic structure of the substorm electrojets. Incoherent scatter radars also offer an excellent technique for the study of both the ionospheric flow velocities and ionospheric particle precipitation during the substorm expansion phase. EISCAT has provided detailed information on the growth and onset of the substorm (e.g. Persson et al., 1994), the conductivity and structure of the westward travelling surge (WTS, Opgenoorth et al., 1989; Olsson et al., 1996), and other dynamic features in the expansion phase (Lühr et al., 1998). The extensive fields-of-view of high frequency (HF) coherent scatter ionospheric radars make them excellent complementary instruments for the investigation of the larger-scale spatial and temporal development of the ionospheric electric fields (e.g. Morelli et al., 1995; Shand et al., 1998; Lewis et al., 1997). This is especially true for the SuperDARN network, which offers an extensive network of such radars in the Northern and Southern Hemispheres. During the substorm expansion phase, such HF coherent radars have observed dynamic convection features, which 
correspond to azimuthally propagating field aligned current systems, which may be related to reconnection and bursty bulk flows in the magnetotail (Yeoman and Lühr, 1997; Yeoman et al., 1998). Localised electrojet features in which ionospheric flows were suppressed to values as low as $50 \mathrm{~m} \mathrm{~s}^{-1}$ and accelerated up to values as high as $1 \mathrm{~km} \mathrm{~s}^{-1}$ within a few minutes have also been observed at the western edge of the substorm-disturbed electrojet, accompanied by conductance variations between 20 and $100 \mathrm{~S}$ (Morelli et al., 1995). Here the capabilities of coherent scatter radars (CUTLASS) and incoherent scatter radars (EISCAT and the EISCAT Svalbard radar, the ESR) are combined to provide a detailed study of the electrodynamics of the first few minutes of evolution of the eastern edge of the substormdisturbed electrojet region at the expansion phase onset.

\section{Instrumentation}

The ionospheric convection velocities in this study are provided by a combination of four ionospheric radar systems, the CUTLASS-Hankasalmi (Finland) and CUTLASS-Pykkvibær (Iceland) radars of the SuperDARN chain of coherent scatter HF radars (Greenwald et al., 1995), the EISCAT VHF radar at Tromsø (e.g. Rishbeth and Williams, 1985) and the EISCAT Svalbard radar (ESR), located at Longyearbyen (e.g. Wannberg et al., 1997). The fields-of-view of these systems during the interval under study are illustrated in Fig. 1.

The SuperDARN radars form 16 beams of separation $3.24^{\circ}$. Each beam is gated into 75 range bins, each of length $45 \mathrm{~km}$ in standard operations. During standard operations the dwell time for each beam is $7 \mathrm{~s}$, giving a full 16 beam scan, covering $52^{\circ}$ in azimuth and over $3000 \mathrm{~km}$ in range (an area of over $4 \times 10^{6} \mathrm{~km}^{2}$ ), every 2 min. For the interval presented here both radars were operating in a non-standard scan mode. The integration time for each beam was reduced to $2 \mathrm{~s}$. This reduced integration time raises the radar data signal-tonoise ratio slightly. The data presented are thresholded as normal at $0 \mathrm{~dB}$, thus the reduced integration period reduces the data coverage, as low returned powers will be lost. In the auroral region, where powerful HF scatter is commonly observed, this has little overall affect on the data coverage. In addition to reduced integration periods, in the scan employed here, rather than the usual anticlockwise (clockwise) sweep through beams $15,14,13, \ldots, 0(0,1,2, \ldots, 15)$ the Hankasalmi (Pykkvibær) radar scanned through the sequence 15,9, $14,9,13,9, \ldots, 1,9,0,9(0,10,1,10,2,10, \ldots, 14,10,15)$. This allows the construction of full 16 beam scans at an enhanced temporal resolution of $64 \mathrm{~s}$, in addition to the provision of very high-time resolution (4 s) data along a single look direction for each radar (in this case beam 9 for Hankasalmi, a beam which approximately overlies the main meridional chain of the IMAGE array, and beam 10 for Pykkvibær).

During the interval of interest, the two EISCAT radar systems were running the UK special programme

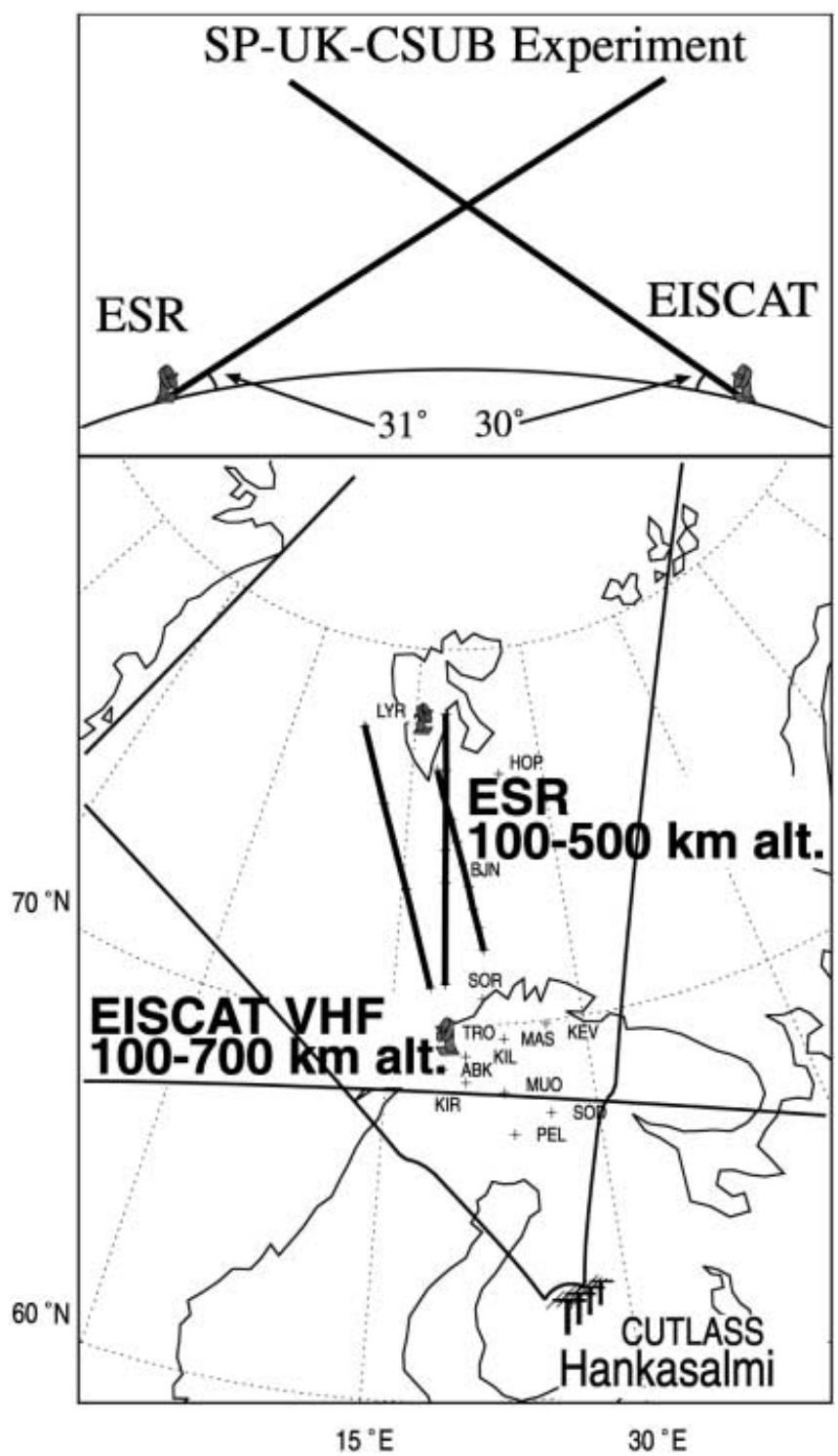

Fig. 1. A diagram of the locations of the ground-based instrumentation used in this study. The lower panel shows the locations of the IMAGE magnetometer stations, along with the ground ranges of the fields-of-view of the CUTLASS Pykkvibær and Hankasalmi radars (the Pykkvibær radar itself lies outside the area of the map). The ground ranges of the fields-of-view of the EISCAT VHF radar (radar ranges $100-700 \mathrm{~km}$ ) and the ESR (radar ranges 100-500 km) for the special programme SP-UK-CSUB are also indicated. The elevations of these two beams are indicated in the top panel

SP-UK-CSUB. This programme was run over four fourhour intervals commencing at 21 UT on 20, 21, 22 and 23 August 1998. The ESR was, during SP-UK-CSUB, directed southward, with a geographic azimuth of $161.6^{\circ}$ and an elevation of $31.0^{\circ}$. This pointing direction allows the ESR beam to be aligned in azimuth along beam 9 of the Hankasalmi radar field-of-view. The ESR was transmitting the GUP0 radar code, a multi-frequency long pulse. Received signals were integrated over $10 \mathrm{~s}$ and the data subsequently analysed at a temporal resolution of $60 \mathrm{~s}$. Analysis of ESR data is such that the user can vary the range resolution, in this case with gating of $12 \mathrm{~km}$ below a range of $330 \mathrm{~km}$, which 
corresponds to an altitude of around $175 \mathrm{~km}$, and $36 \mathrm{~km}$ range gates above $330 \mathrm{~km}$; ESR observations span the altitude range from 110 to $500 \mathrm{~km}$.

In SP-UK-CSUB, the EISCAT VHF radar operated in a split beam mode with one beam (beam 2) directed along the boresight which corresponds to a geographic azimuth of $359.5^{\circ}$ and the other (beam 1) phased $14.5^{\circ}$ west to an azimuth of $345.0^{\circ}$; both beams are at a elevation of $30^{\circ}$. In SP-UK-CSUB, which is identical to the VHF common programme CP-4, long pulse and power profile codes are transmitted. The long pulse provides observations, on each beam, over 20 gates of range resolution $65.3 \mathrm{~km}$ with the first gate centred at a range of $533.0 \mathrm{~km}$; this corresponds to an altitude coverage from around $280 \mathrm{~km}$ to over $1000 \mathrm{~km}$. The power profile pulse scheme yields returned power measurements at a range resolution of $4.5 \mathrm{~km}$ over 83 gates the first of which corresponds to an height of some $85 \mathrm{~km}$. Like those from Svalbard, VHF observations were analysed at 1 min temporal resolution. Beam 1 of the VHF radar is aligned in azimuth along beam 7 of the Hankasalmi radar whereas beam 2 crosses beams 8,9 and 10 of the Hankasalmi radar.

Standard analysis of the long pulse signal from both the Svalbard and VHF radars provide estimates along each beam of both ion and electron temperature, electron density and ion velocity. Moreover, estimates of the Hall and Pedersen conductance can be derived from the VHF power profile measurements with the incorporation of appropriate input from the MSIS-90 thermospheric model and the IGRF model of the geomagnetic field.

Data from the far ultraviolet imager (UVI) instrument carried by the Polar spacecraft (Torr et al., 1995) is also examined. This instrument measures auroral emission in the Lyman-Birge-Hopfield system of bands, the result of electron impact excitation of $\mathrm{N}_{2}$, with two filters, LBHl and LBHs, which are centred on $1700 \AA$ and $1500 \AA$, respectively. The auroral features under study appear in both the LBHl and LBHs observations, though are perhaps clearer in LBHs and hence it is these images which will be presented. An image is acquired every $3 \mathrm{~min}$, with an integration period of $37 \mathrm{~s}$.

This data set is supplemented here by data from ground-based fluxgate magnetometers, provided by stations from the International Monitor for Auroral Geomagnetic Effects, IMAGE) (Lühr, 1994). The IMAGE array has $10 \mathrm{~s}$ sampling for the interval under consideration here. The IMAGE data is presented in $X$, $Y, Z$ co-ordinates, where $X$ is geographic northwards, $Y$ geographic eastwards and $Z$ is vertically downwards.

\section{Observations}

\subsection{Wind}

Magnetic field data (Lepping et al., 1995) from the Wind spacecraft upstream in the solar wind are presented in Fig. 2. Wind was at coordinates $80,-33,-5 R_{E}(X, Y, Z$ GSE) at the time of interest. The observed solar wind

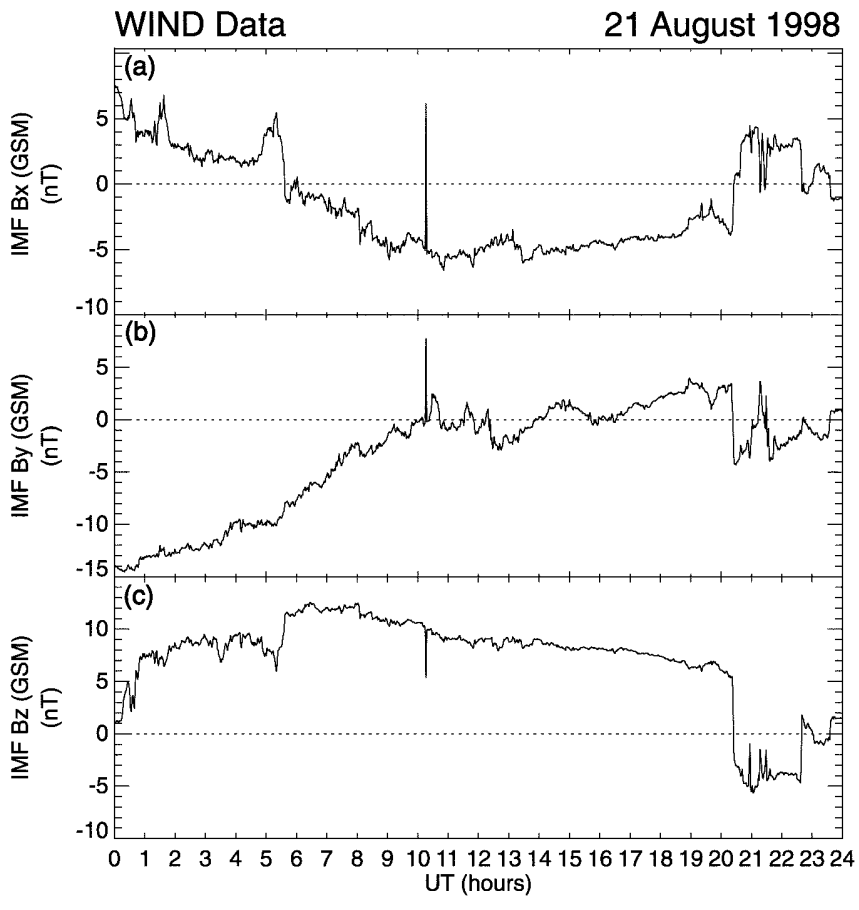

Fig. 2. Data from the Wind spacecraft upstream in the solar wind for the interval 0000-2400 UT on the 21st August, 1998. Panels $a-c$ show the $X, Y$ and $Z$ component magnetic field data in GSM coordinates

velocity of $\sim 300 \mathrm{~km} \mathrm{~s}^{-1}$ suggests that a delay from the spacecraft to the subsolar magnetopause of $\sim 33 \mathrm{~min}$ is appropriate. Prior to 2025 UT on August 21, 1998, the IMF had been northward for $20 \mathrm{~h}$. The IMF $B_{y}$ component was positive for $4 \mathrm{~h}$ prior to $2025 \mathrm{UT}$. At 2025 UT ( 2058 UT at the magnetopause) both the $B_{y}$ and $B_{z}$ components abruptly switched polarity, turning negative. The IMF remained in this configuration until 2238 UT, ( 2311 UT at the magnetopause) when the IMF $B_{z}$ component became close to zero, although the IMF $B_{y}$ component did have a brief excursion to positive values at $2118 \mathrm{UT}$. Assuming a further $2 \mathrm{~min}$ delay for the effect of the IMF southward turning to reach the ionospheric footprint of the subsolar magnetopause, and $15 \mathrm{~min}$ for the subsequent reconfiguration of the ionospheric convection pattern to expand to the nightside (Cowley and Lockwood, 1992), the effects of the southward turning would be expected to reach the nightside ionosphere at $\sim 2115$ UT. Some time after this, at 2140 UT, measurements of the equatorward boundary of the Hankasalmi HF radar backscatter are first available (prior to this the data is masked by ground scatter), and can be seen to be migrating equatorward at this time. This is a phenomenon previously associated with the substorm growth phase (Lewis et al., 1997), and is discussed further in Sect. 4.

\subsection{Ground magnetometer data}

$X, Y$ and $Z$ component magnetic field data from the IMAGE array between 2000-2400 UT on the 21st August, 1998 is presented in Fig. 3. Magnetically quiet 
IMAGE 980821

\section{(a) $\mathrm{X}$}

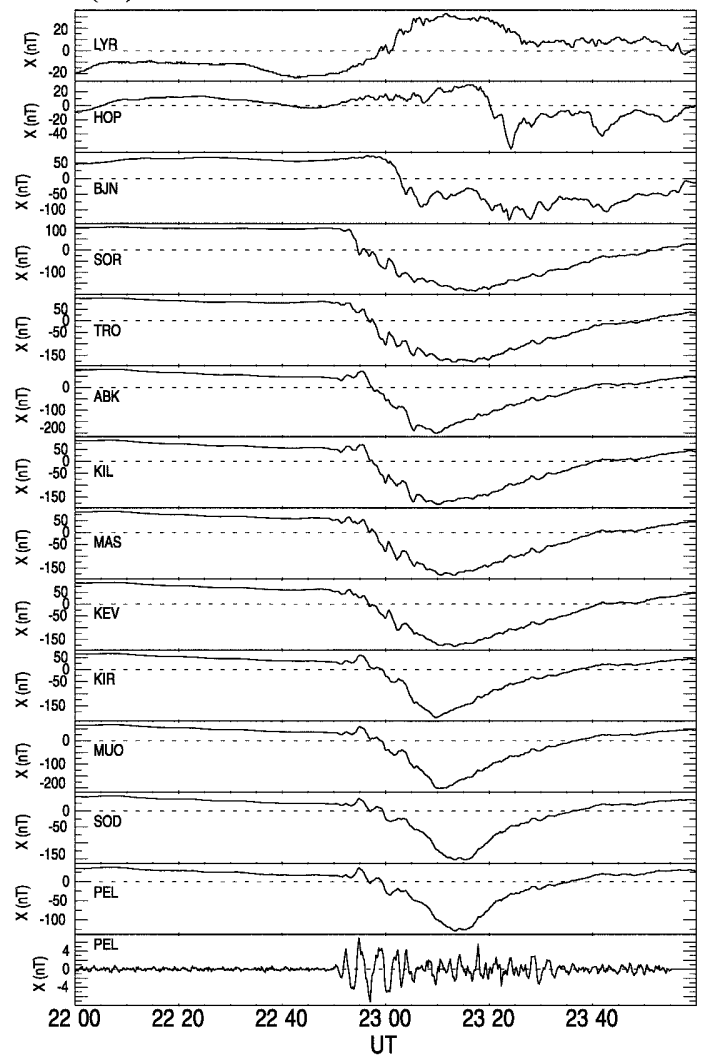

(c) Z

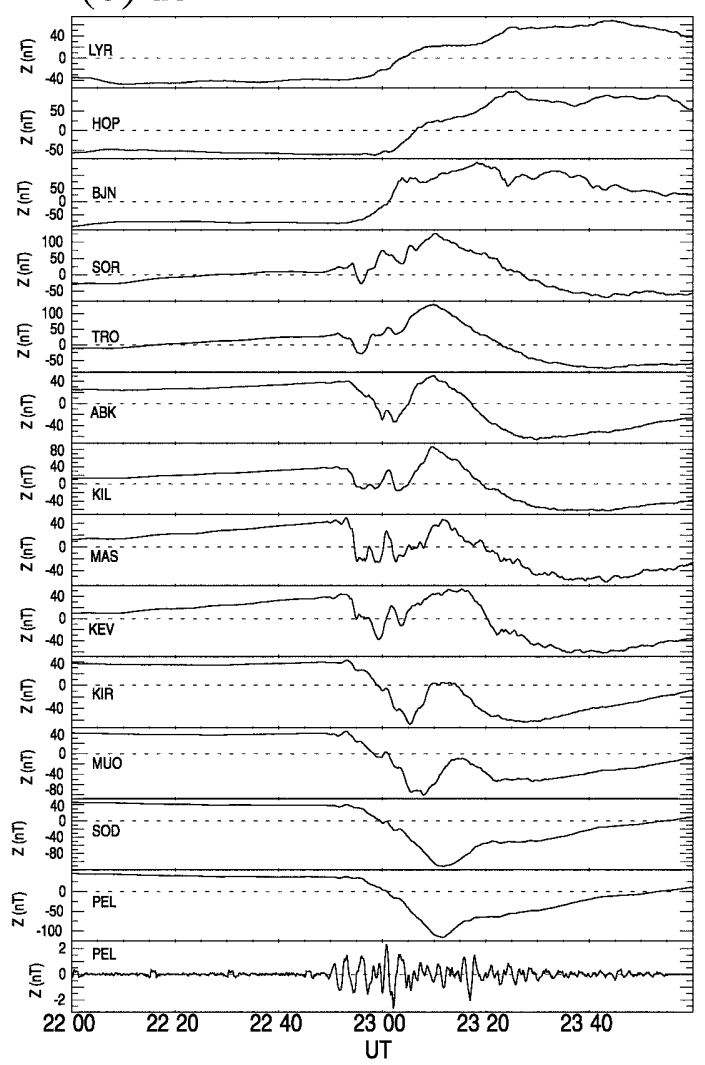

(b) $Y$

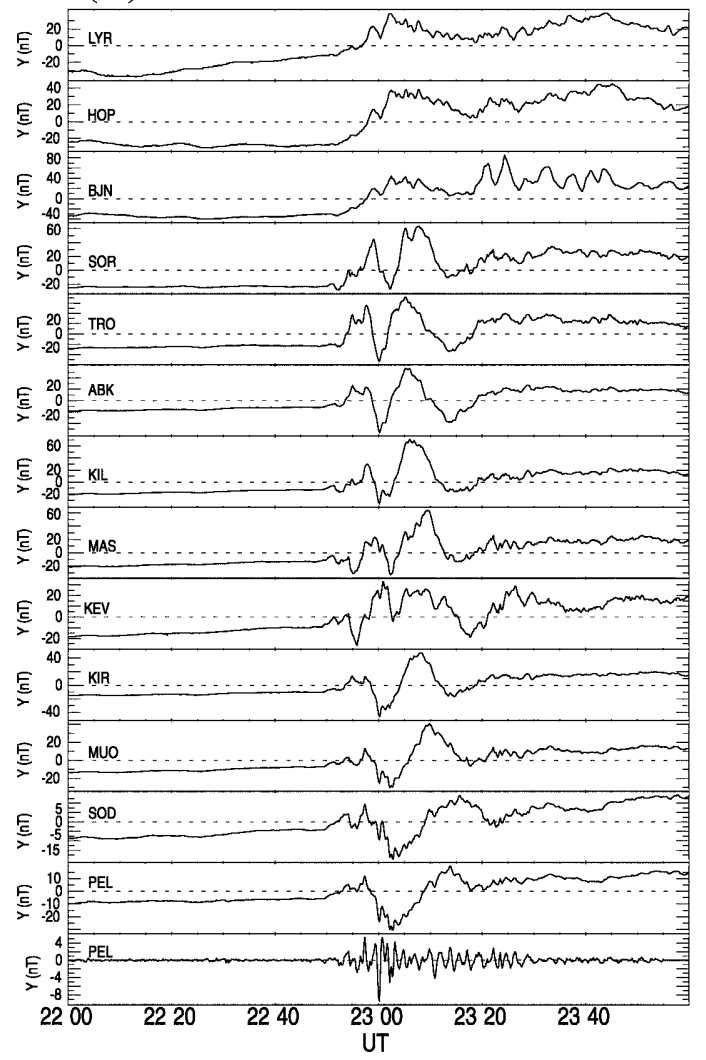


conditions apply up to $2250 \mathrm{UT}$, when a clear midlatitude Pi2 pulsation, indicating the substorm expansion phase onset, is observed, with a further Pi2 burst at 2305 UT. The onset of the first $\mathrm{Pi} 2$ burst coincides with a strong negative bay (up to $300 \mathrm{nT}$ ) in the $X$ component auroral magnetograms, indicating a substorm-enhanced westward electrojet. The onset of this magnetic disturbance in the $X$ component can be seen to propagate poleward, reaching BJN at $2258 \mathrm{UT}$ and HOP at 2318 UT. In the mainland Scandinavian magnetometer stations the $Z$ component magnetograms similarly show a negative disturbance at 2250 UT. Poleward, this $Z$ component response is positive, only deviating negative when the westward electrojet signature has propagated poleward, as outlined already. After 2250 UT, at lower latitudes, complex $Z$ component disturbances are observed until $2310 \mathrm{UT}$, when the substorm electrojet is clearly centered north of the mainland magnetometer stations. In the $Y$ component, two large positive excursions are observed, centred at 2300 and 2308 UT. Such features are usually associated with auroral loop and surge features (see relevant parts of Sect. 4, Untiedt and Baumjohann, 1993 and references therein), and in this case an eastward motion may be calculated from the azimuthally separated stations KIL, MAS and $\mathrm{KEV}$, to be $\sim 0.6 \mathrm{~km} \mathrm{~s}^{-1}$. It is the electrodynamics of these two surge features which are the focus of the present study.

\subsection{EISCAT, ESR and Hankasalmi data}

Data from the ESR radar is presented in Fig. 4. The four panels present electron density, electron temperature, ion temperature and line-of-sight ion velocity data from the radar, as a function of geomagnetic latitude and time (Altitude Adjusted Corrected Geomagnetic coordinates, AACGM, based on Baker and Wing, 1989, are used throughout this study). Line-of-sight velocity data from the ESR is colour-coded with blue representing flow away from the radar (equatorward flow) and red flow toward the radar (poleward flow). In subsequent plots data from the Hankasalmi radar are colourcoded with blue representing flow toward the radar (equatorward flow) and red flow away from the radar (poleward flow). This colour scheme is chosen to give consistent colour coding in plots of data from both radar systems. The ESR beam has an elevation of $31^{\circ}$, so the panels in Fig. 4 cover $750-350 \mathrm{~km}$ altitude.

Before 2250 the ionosphere is relatively undisturbed, with a pair of equatorward drifting arcs, most easily distinguished as enhancements in the electron and ion temperature data, propagating away from the radar between 2120 and 2220 UT. Such features are characteristic of the substorm growth phase (Persson et al., 1994). At 2250, the time of the substorm onset, there is no immediate response apparent in the ESR data, with very low line-of-sight velocities being measured. However, at 2300 UT, a sudden increase in the negative (equatorward) line-of-sight velocity is observed below $70^{\circ}$ latitude, accompanied by a short-lived burst of greatly enhanced ion temperatures, as expected for intervals of large electric field, and elevated electron temperatures, indicative of enhanced particle precipitation. This region of enhanced flow and precipitation expands poleward at $0.9 \mathrm{~km} \mathrm{~s}^{-1}$ initially, slowing to $0.6 \mathrm{~km} \mathrm{~s}^{-1}$ by $71.5^{\circ}$ latitude. This poleward-expanding auroral feature finally reaches a latitude of $72.5^{\circ}$, and is visible in both the beams of the EISCAT VHF radar (not shown) as well as in the ESR data. The polewardexpanding auroral feature results in a depletion of the F-region electron density (Fig. 4a). Such density depletions are frequently observed in conjunction with ion frictional heating (e.g. Williams and Jain, 1986; Davies et al., 1995). The reduction in the F-region electron density is generally ascribed to a combination of two factors, increased plasma recombination and enhanced field-aligned flows. During the subsequent hour of the expansion phase there are a number of shortlived bursts of poleward flow, before the convection in general turns poleward.

The relationship between the precipitation regions and the region of enhanced flow velocities is examined in more detail in Fig. 5, which presents the electron temperature and ion velocity from the ESR, together with high-time resolution velocity data from the Hankasalmi radar, measured at the same azimuth and latitude range, between 2230 and 2330 UT. The poleward expansion of the region of electron temperature and enhanced equatorward velocities after 2300 UT are remarkably similar. Before this a sudden change in the equatorward flow velocity at $2254 \mathrm{UT}$ is observed, most clearly in the high-time resolution data from Hankasalmi. This velocity drop is observed essentially simultaneously at latitudes below $72^{\circ}$ some $6 \mathrm{~min}$ before the poleward expanding region of enhanced precipitation moves into the ESR field of view. The region of low velocity is followed by an interval of data loss from the Hankasalmi radar, possibly due to a loss of ionospheric irregularities in the very low electric field region (Milan et al., 1999). The increasing strength of the equatorward flows at 2300 UT see the Hankasalmi data returning, and a further sudden velocity decrease is observed at 2305 UT. This velocity decrease is also visible in the ESR data. Subsequent to this feature an extended data gap appears in the Hankasalmi data, probably as a result of changing $\mathrm{HF}$ propagation conditions.

The changes in line of sight velocity measured at a time resolution of $4 \mathrm{~s}$ by the Hankasalmi radar can be most easily observed in a simple time series format. Figure 6 presents such a plot, between 2245 and 2315 UT, with positive velocity measuring flow toward the radar. Data from every other range cell is shown for clarity, and data from lower latitudes that those in Figs. 4 and 5 are included (colour-coded velocity measurements from these latitudes are shown later in Fig. 11). The $Y$ component magnetic field measured at SOR is included for comparison. The two times when there is a sharp, near-simultaneous change in equatorward flow over an extended region of latitude are marked with dashed vertical lines. At higher latitudes the equator- 


\section{EISCAT Longyearbyen SP-UK-CSUB}

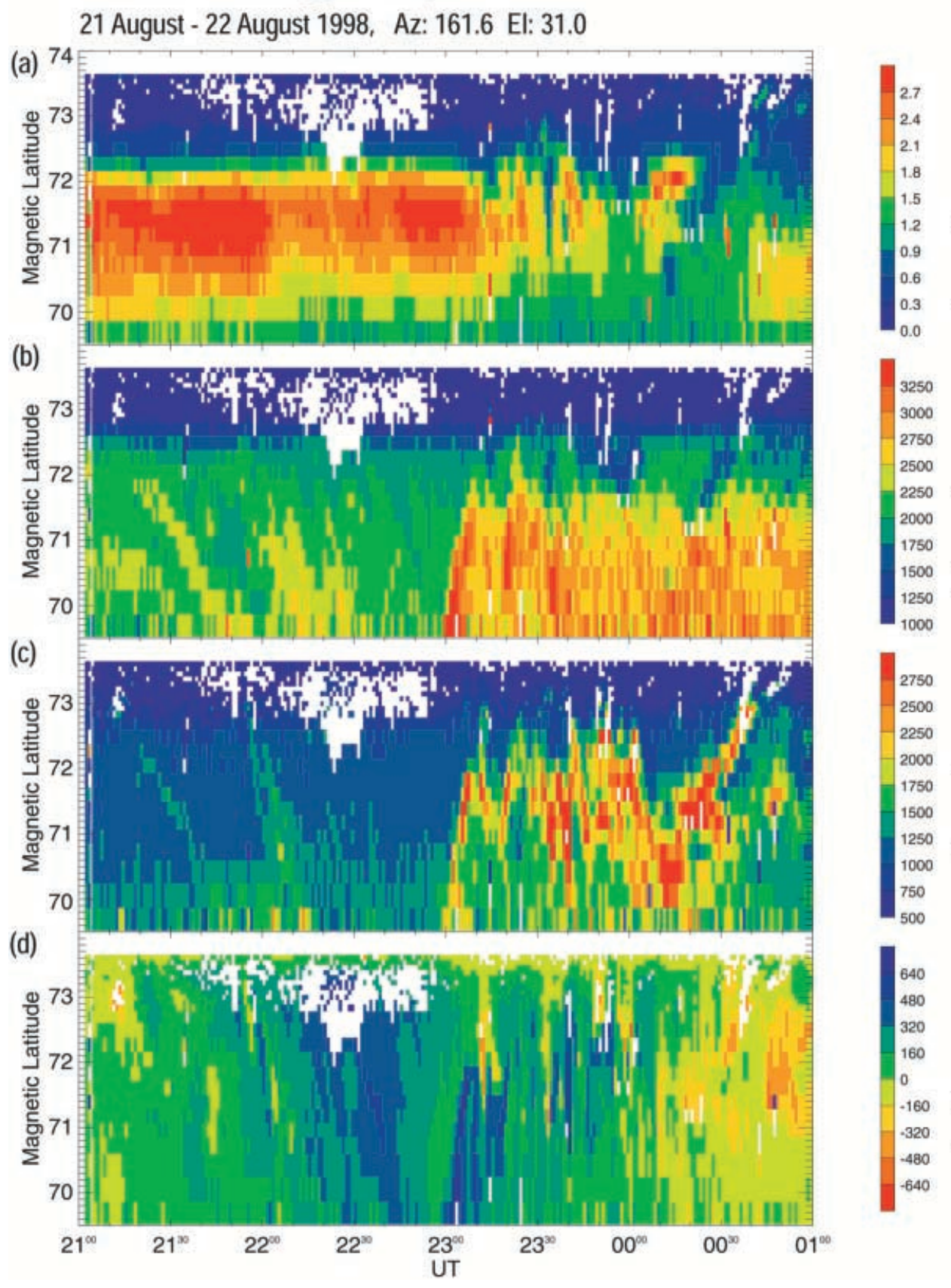

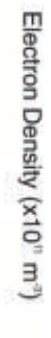

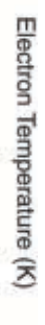

$\overline{\mathrm{g}} \quad$ Fig. 4a-d. A latitude-time-parameter representation of data from the ESR, 2100 on the 21st August to 0100 on the 22nd August, 1998. a Electron density, b electron temperature, $\mathbf{c}$ ion temperature, d line-of-sight ion velocity. Line-of-sight velocity data from the ESR is colourcoded with blue representing flow away from the radar (equatorward flow) and red flow toward the radar (poleward flow). In subsequent plots, data from the Hankasalmi radars are colourcoded with blue representing flow toward the radar (equatorward flow) and red flow away from the radar (poleward flow). This colour scheme is chosen to give consistent colour coding in plots of data from both radar systems ward flow decreases, whereas at the lowest latitudes there is some evidence for an increase in the equatorward flow. The transition region between these regimes is at $68.3^{\circ}-69.1^{\circ}$ geomagnetic latitude. These sharp changes in ionospheric flow velocity occur near the beginnings of the intervals of positive $Y$ component magnetic disturbances measured at SOR.

Additional information on the ionospheric flows and particle precipitation during this interval may be obtained from the EISCAT VHF radar system. Figure 7 presents velocity measurements obtained from a beamswinging analysis of the line of sight ion velocity data from the two VHF beams illustrated in Fig. 1. In the beam-swinging process the data from the two beams of the EISCAT VHF radar are actually measured simultaneously, and the line-of-sight velocities in the two look directions from a given geomagnetic latitude are combined together under the assumption of spatial uniformity between the appropriate range cells. These beam-swung velocities are overlaid on colour-coded Hankasalmi line-of-sight velocities from beam 7, which is close to the VHF beam locations. The beam-swung velocity measurements show a predominantly equatorward velocity orientation, and the intervals of flow suppression at 2254 and 2305 UT are clearly visible. Where the EISCAT VHF beams are at an appropriate 


\section{EISCAT Longyearbyen SP-UK-CSUB}

21 August - 22 August 1998, Az: 161.6 El: 31.0

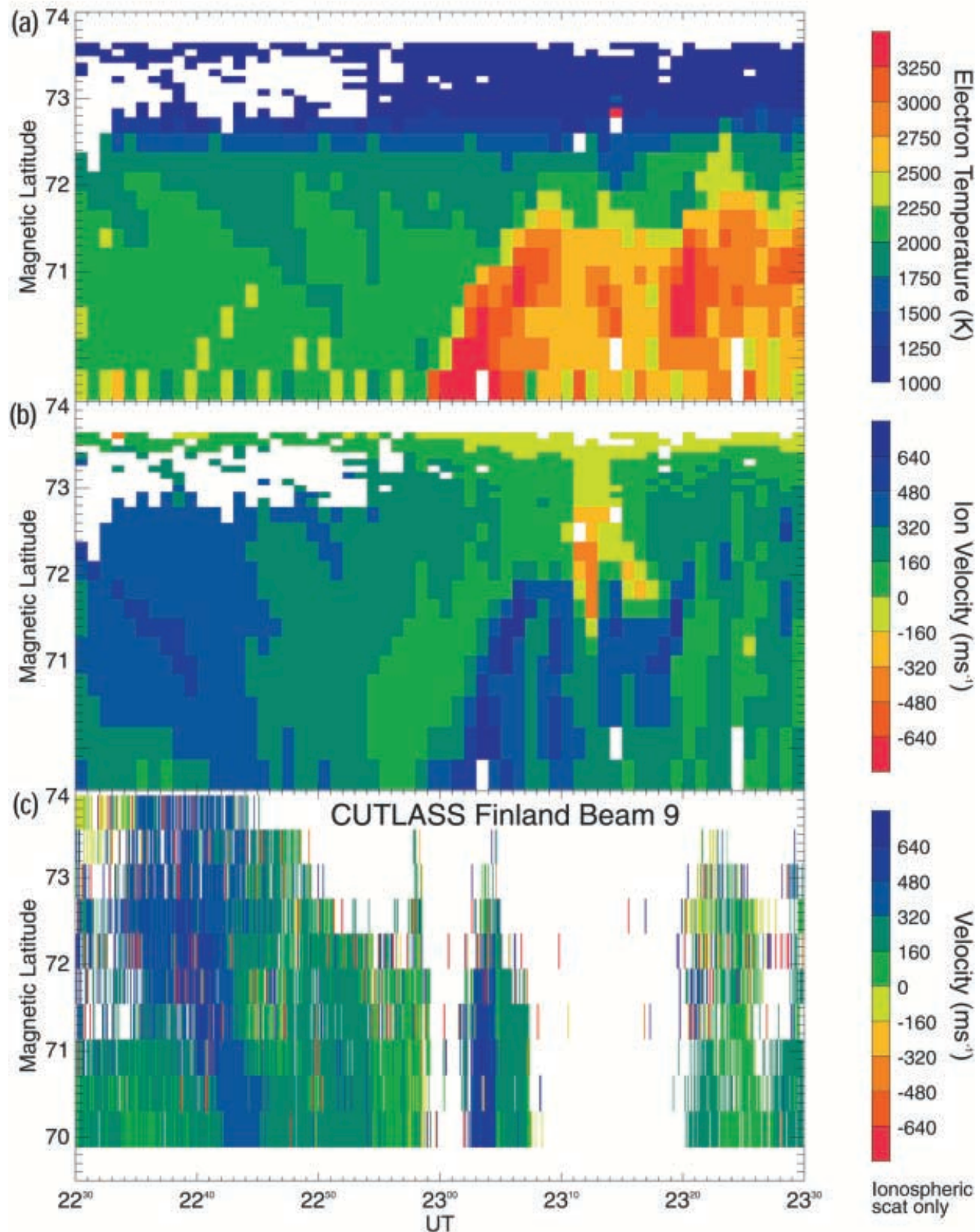

Fig. 5a-c. A latitude-time-parameter representation of data from the ESR and Hankasalmi, 2230-2330 UT on the 21st August, 1998. a ESR electron temperature, b ESR line-of-sight ion velocity. c Hankasalmi beam 9 line-of-sight velocity. Colour coding is as described for Fig. 4 altitude, they can also give an estimate of the ionospheric conductivities. Inspection of the radar power profiles (not shown) reveals the measured conductivities to be dominated by the ionosphere at $68.0-68.5^{\circ}$ latitude, where the radar beam passes through the $\mathrm{E}$ region ionosphere, due to the VHF beam elevation of $30^{\circ}$. The interval after the substorm expansion phase onset is clearly characterised by enhanced Hall conductance, particularly at the times of velocity reduction noted at higher latitudes in Fig. 5, at 2254 UT, and subsequently after 2305 UT. At 2254 UT the Hall conductivity increases rapidly from $\sim 3 \mathrm{~S}$ to $12 \mathrm{~S}$, whilst the Pedersen conductivity increased from $\sim 1$ to $5 \mathrm{~S}$.

\subsection{SuperDARN convection maps and Polar UVI}

The detailed measurements of the ionospheric flow velocities and particle precipitation regions provided by the EISCAT, ESR and Hankasalmi beam 9 observations in Sect. 3.3 may be put into context by twodimensional observations of ionospheric flows and auroral intensity from the CUTLASS pair of SuperDARN radars and the Polar UVI instrument, respectively. Figure 8 presents a magnetic local time (MLT) magnetic latitude representation of data from both these instruments for two intervals during the substorm expansion phase onset. These times are chosen to 


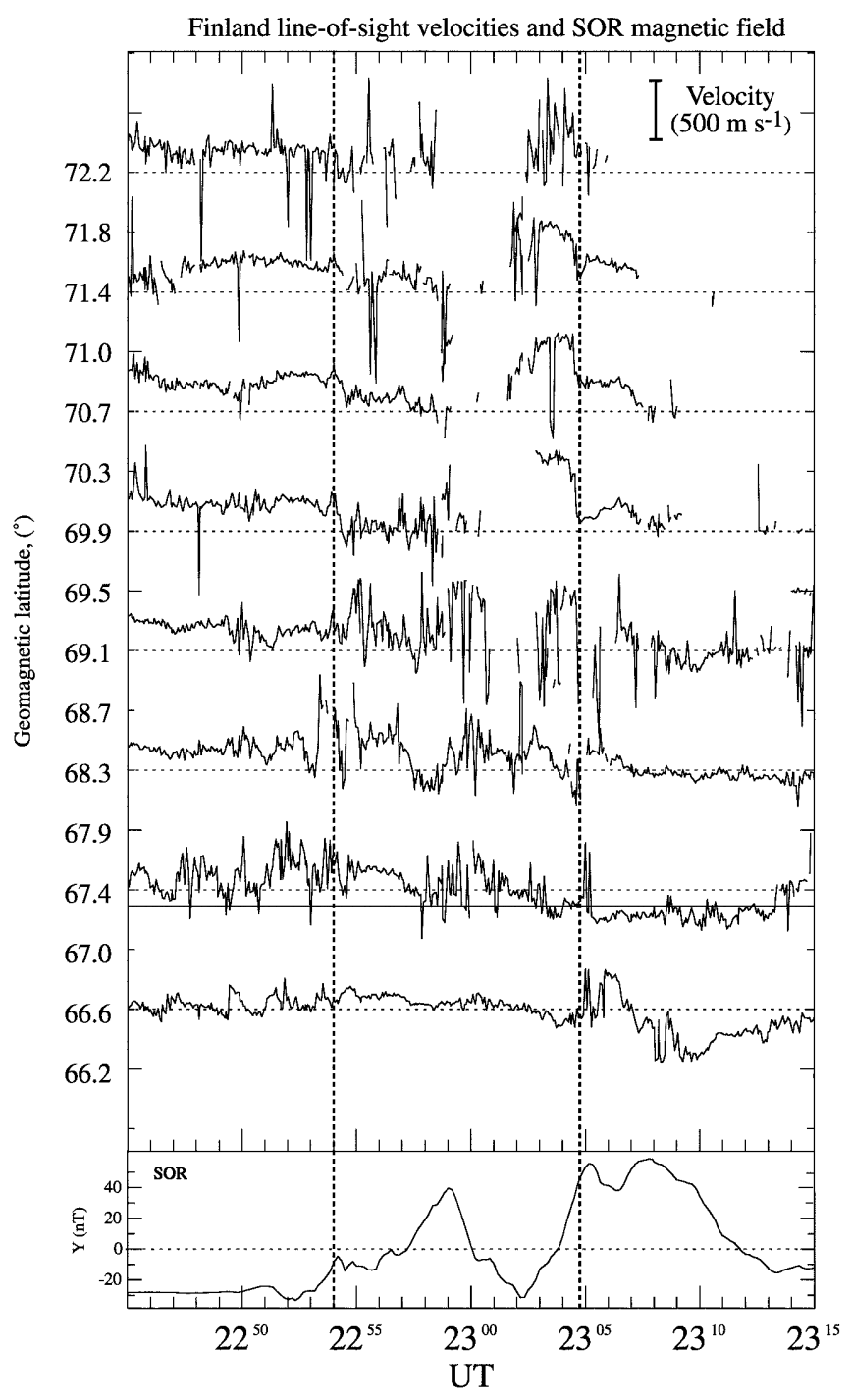

Fig. 6. Line-of-sight velocities from beam 9 of the Hankasalmi radar, 2245-2315 UT, on the 21st August, 1998. For clarity, data from every other range cell are displayed. Positive velocities represent flow toward the radar (equatorward flow). The lower panel shows the $Y$ component magnetic field data from SOR for comparison. The latitude of SOR is marked in the upper panel by a horizontal solid line. Impulsive changes in the ionospheric convection are indicated with dashed vertical lines

coincide with Polar images. Figure 8a shows Polar UVI auroral intensity data for scans beginning 2253:53 and 2303:05 UT. A number of estimates of the horizontal flow vector, calculated using a beam-swinging algorithm where the flow component parallel to the $L$-shell is assumed constant across the scan (Villain et al., 1987; Ruohoniemi et al., 1989) are overlaid. These velocity vectors are derived from beam-swinging constrained by measurements from both the Pykkvibær and Hankasalmi radars (the line-of-sight data from which is shown in Fig. 8b and c respectively). Ideally bistatic velocity vectors would be used to examine the two-dimensional ionospheric flow patterns, but such data are scarce from HF radars during substorms. To present the clearest picture we therefore present full scans of line-of-sight velocities, in addition to beam-swung vectors, and also use the potential map technique, as described later. These approaches produce largely consistent results. The first column of Fig. 8, at close to 2254 UT, shows the time when the substorm expansion phase onset initially suppressed the ionospheric flow. The auroral intensity can be seen to start as a small intense region at about $68^{\circ}$ latitude and 0030-0200 MLT. At this time, low ionospheric flows are observed, with equatorward flow dominant. A westward flow component exists at higher latitudes and an eastward component at lower latitudes. The second column of Fig. 8 presents data from 2303 UT, when the flow magnitudes have increased during the substorm expansion phase. The auroral observations can be seen to have expanded rapidly westwards. The ionospheric flows have strengthened considerably. A predominantly eastward component is now observed, with equatorward flow in the west and poleward flow in the east. These regions of rapid flow encircle the equatorward edge of a region of low flow in the centre of the Hankasalmi field of view.

An alternative technique for the visualisation of the ionospheric convection patterns during the interval is presented in Fig. 9. Here the spherical harmonic potential fitting or "potential map" technique (Ruohoniemi and Baker, 1998) has been applied to calculate the potential pattern which is most consistent with the lineof-sight velocities determined by the Hankasalmi and Pykkvibær radars. In Fig. 9 three $64 \mathrm{~s}$ intervals are presented in MLT-geomagnetic latitude coordinates for latitudes ranging from $60^{\circ}$ to $80^{\circ}$ and local times from 21 to 03 MLT. Contours of electric equipotentials are displayed, with solid (dashed) lines indicating negative (positive) potentials. Ionospheric flow vectors are also displayed. These are deduced from the combination of the measured line-of-sight velocities and beam-perpendicular flows derived from the calculated ionospheric potential pattern. In these maps the electric potential is expanded to order 8 , with the lower latitude limit of the convection pattern fixed to $60^{\circ}$. No temporal median filtering has been applied. The potential pattern calculation is stabilised by the statistical model of Ruohoniemi and Greenwald (1996) for the prevailing IMF conditions measured by Wind, with a time delay of $50 \mathrm{~min}$. In fact the calculated equipotential pattern is insensitive to the exact upstream conditions assumed.

Figure $9 \mathrm{a}$ presents the convection pattern from 2251:04-2252:08 UT, just before substorm expansion phase onset. A typical, fairly symmetrical two-cell convection pattern can be observed. Figure 9b, shows data from 2255:20-2256:24 UT, a little later than Fig. 8a, and at a time when the suppression of ionospheric electric field has fully developed, and hence the reduced flow magnitudes are clearly illustrated by a "pushing apart" of the equipotential contours just after local midnight. Figure 9c (2303:52-2304:56 UT) shows a strengthening ionospheric electric field with the pattern of flow deduced from Fig. 8c pushing eastwards into the dawn convection cell. 


\section{SP-UK-CSUB}

Finland: vel

Beam 7

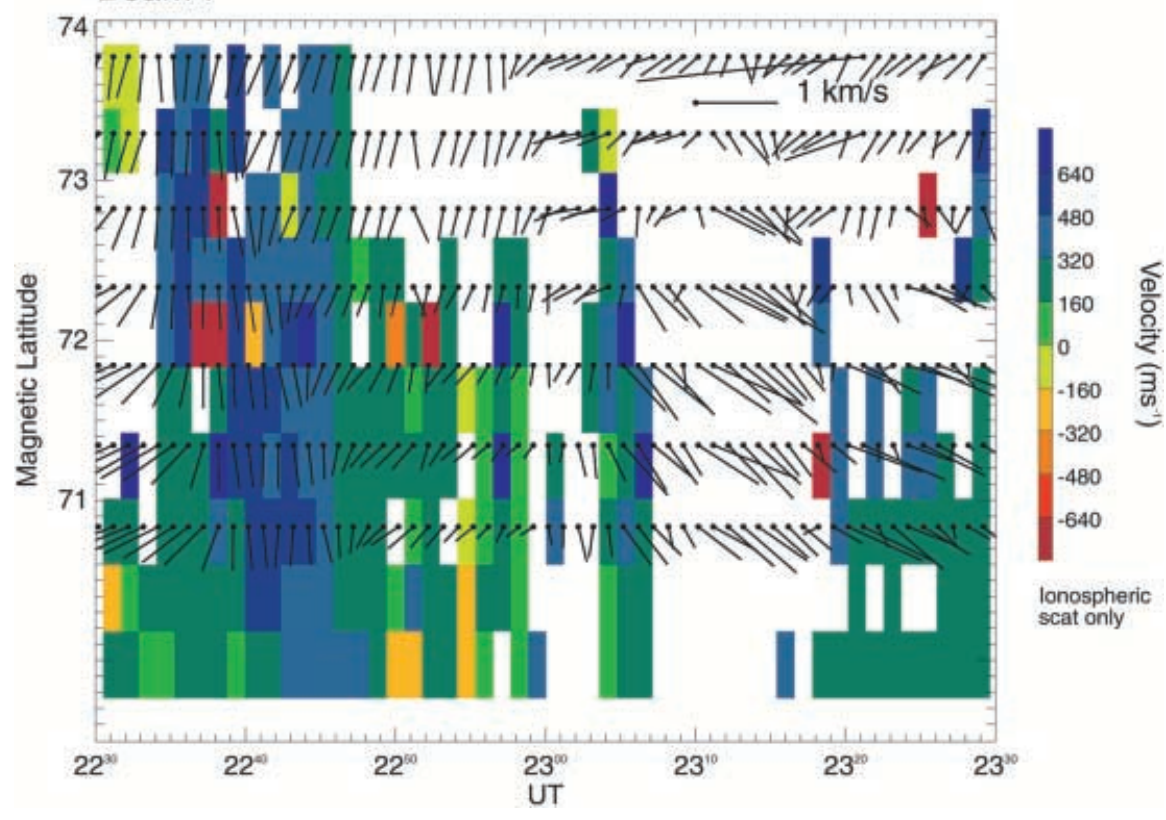

21 Aug 1998

๙ิ

Fig. 7. Line-of-sight velocity from beam 7 of the Hankasalmi radar, 2230-2330 UT on the 21st August, 1998. Colour coding is as described for Fig. 4. Superposed on the colour coding is a vector representation of the velocity from the two beams of the EISCAT VHF radar, deduced from a beamswinging approximation

\section{Discussion}

This interval presented here provides some uniquely well instrumented observations of a "classical" isolated substorm. Prior to a sharp southward turning of the IMF, a $20 \mathrm{~h}$ interval of northward IMF had prevailed, and such a situation should remove many of the complexities introduced by fluctuating dayside conditions and multiple substorm onsets.

At 2025 UT both the $B_{y}$ and $B_{z}$ components of the IMF measured at Wind abruptly switched polarity, turning negative. Allowing for the propagation of this IMF rotation through the solar wind, magnetosheath and magnetosphere leads to an expected commencement of the substorm growth phase at 2115 UT. Up to 2140, ground scatter obscures the lower latitude data from the SuperDARN Finland radar. From this time on, however, the equatorward edge of the scatter can be seen to progress steadily equatorward. This is a classic signature of the substorm growth phase in HF radar data (Lewis et al., 1997), at least for isolated substorms.

A pair of auroral arcs, most easily distinguished as enhancements in the electron and ion temperature data in the ESR data in Fig. 4, are observed to propagate equatorward away from the radar at $200-400 \mathrm{~m} \mathrm{~s}^{-1}$, between 2120 and 2220 UT. These drift speeds are consistent with the background ionospheric flow velocity, although the peak flow in the vicinity of the arcs is $\sim 1.2 \mathrm{~km} \mathrm{~s}^{-1}$. Such features are also characteristic of the substorm growth phase (Persson et al., 1994). Thus we can conclude that the substorm growth phase commenced close to $2115 \mathrm{UT}$, and had a duration of $1 \mathrm{~h}$ $35 \mathrm{~min}$, with the first signs of the substorm expansion phase onset occurring at $2250 \mathrm{UT}$, as manifested by a
Pi2 pulsation and a clear, poleward expanding auroral disturbance (Fig. 3).

Shortly after the Pi2 pulsation, the ESR detected a poleward-expanding region of enhanced electron temperature, which is expected to accompany an auroral form (such incoherent scatter radar observations of poleward expanding substorm aurora are relatively rare (Lühr et al., 1998)), and Polar UVI also detects a colocated poleward-expanding optical aurora. The location of the initial disturbance is at $65^{\circ}$ geomagnetic latitude (Fig. 8a) and thus would map to a location in the near-Earth magnetotail as suggested by e.g. Samson et al. (1992), Samson (1994), and Yeoman et al. (1994). The poleward expanding auroral structure moves initially at $0.9 \mathrm{~km} \mathrm{~s}^{-1}$ poleward, slowing to $0.6 \mathrm{~km} \mathrm{~s}^{-1}$ by $71.5^{\circ}$ latitude. This poleward-expanding auroral feature finally reaches a latitude of $72.5^{\circ}$. This propagation is consistent with the magnetic signatures observed on the IMAGE magnetometer array. The ionospheric convection and height integrated conductivity in the vicinity of the expanding substorm region exhibit a number of characteristic features. Typical flows of $600 \mathrm{~m} \mathrm{~s}^{-1}$ and conductances of $2 \mathrm{~S}$ before the auroral activation give way to values of $\sim 100 \mathrm{~m} \mathrm{~s}^{-1}$ and $10-20 \mathrm{~S}$ respectively. These values are consistent with previous measurements with EISCAT and with HF radars, which have suggested that typical values of flow and conductance within the substorm-disturbed electrojet are $50-200 \mathrm{~m} \mathrm{~s}^{-1}$ and 20 100 S (Morelli et al., 1995; Olsson et al., 1996; Yeoman and Lühr, 1997; Lühr et al., 1998). Previous measurements have employed either incoherent or coherent scatter radars, and have had a temporal resolution of no better than $1 \mathrm{~min}$. Here the two techniques are available together, and a temporal resolution of $4 \mathrm{~s}$ is available 


\section{SUPERDARN PARAMETER PLOT}

CUTLASS velocity and Polar UVI

\section{Aug 1998}

(a)
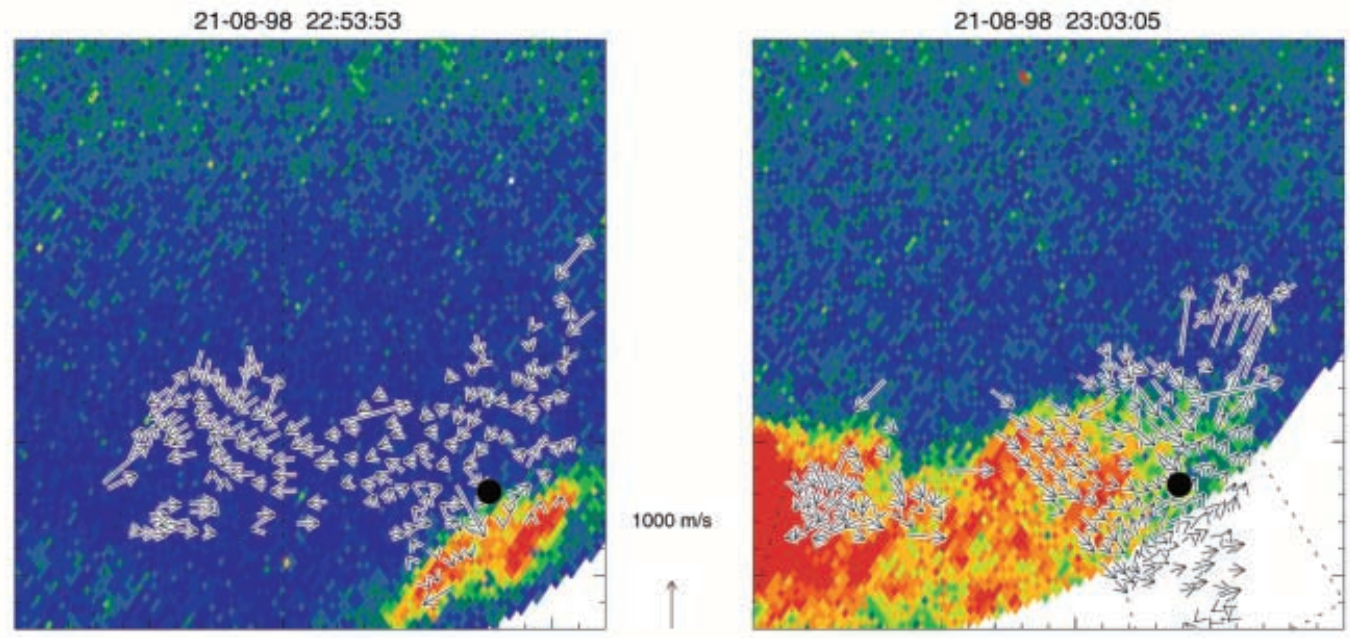

(b)

225352 s (233)

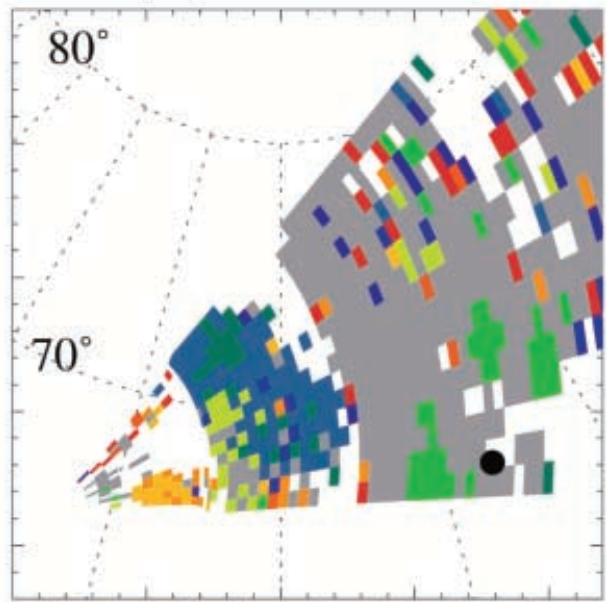

23 MLT 00 MLT

225334 s (233)

(c)

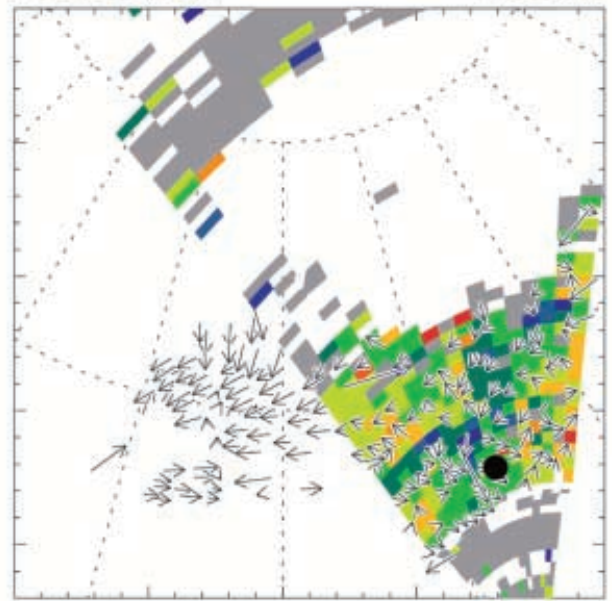

$9.985 \mathrm{MHz}$

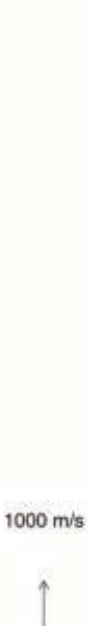

230305 s (233)
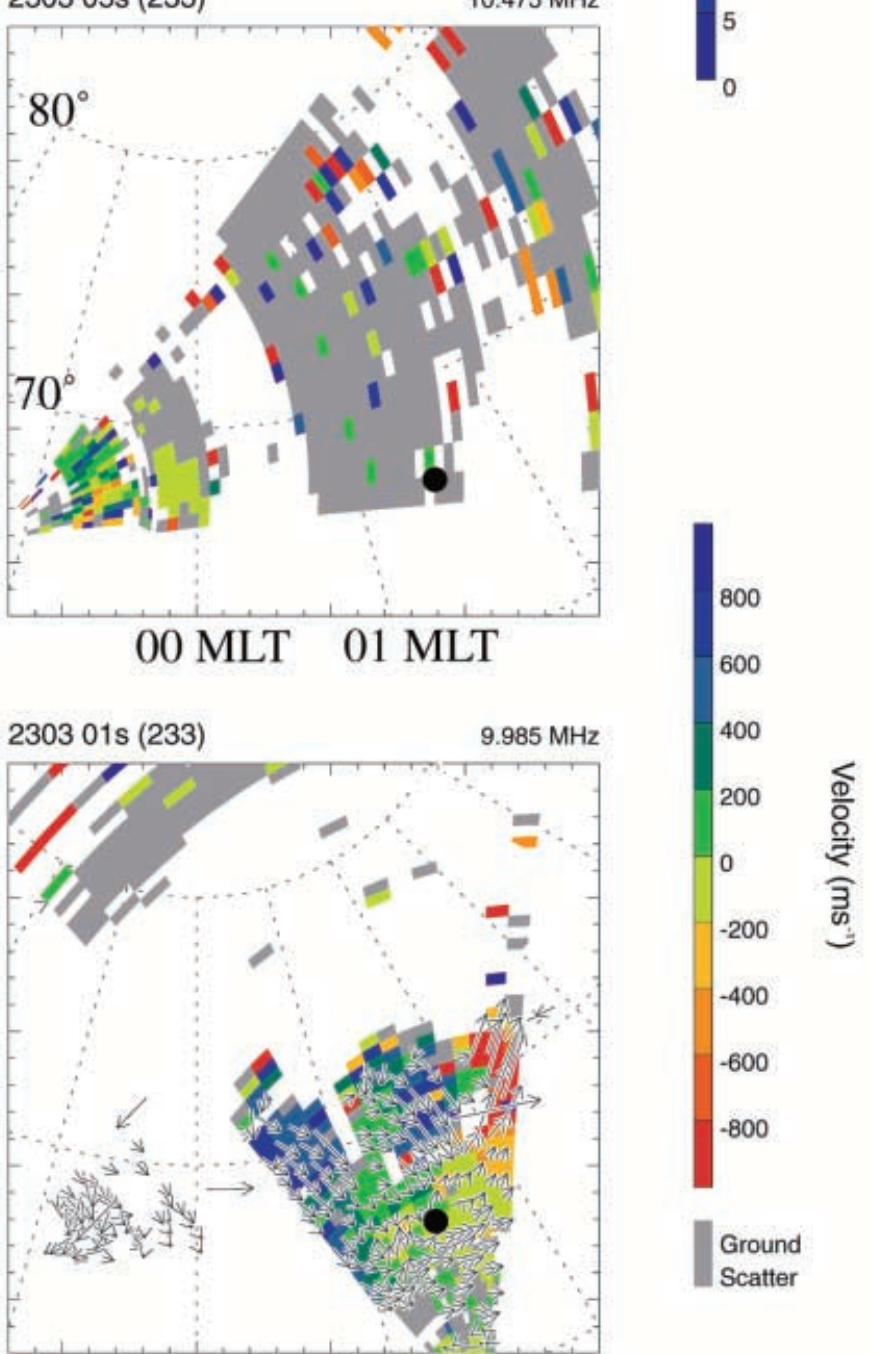

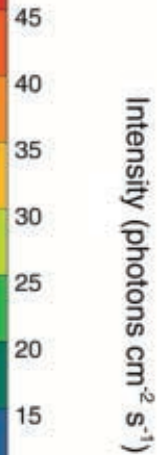

800

600

400

200

萬

$-400$

$-600$

$-800$

Ground

Scatter 
Fig. 8a-c. Magnetic local time-Magnetic latitude representation of CUTLASS velocity and Polar UVI auroral data. a Polar UVI auroral intensity data for scans beginning 2253:53 UT and 2303:05 UT. Velocity vectors derived from a beam-swinging technique using both the Pykkvibær and Hankasalmi radars (scans shown in b and $\mathbf{c}$ respectively) are overlaid (see text for details). b Line-of-sight velocities from the Pykkvibær radar, colour coded with positive velocities blue (toward the radar) and negative velocities red (away from the radar), for scans beginning 2253:52 UT and 2303:05 UT. c Line-of-sight velocities from the Hankasalmi radar, colour coded with positive velocities blue (toward the radar) and negative velocities red (away from the radar), for scans beginning 2253:34 UT and 2303:01 UT. The beam-swung velocity vectors from a are superimposed. The location of the SOR magnetometer is marked with a dot in each panel

from beam 9 of the Hankasalmi radar. This combination of instruments reveals that at the moment of onset of the impulsive electrojet region, the equatorward flow is very rapidly suppressed, over a time scale of $\sim 10 \mathrm{~s}$ (most clearly illustrated in Fig. 6). Furthermore, the flow suppression is nearly simultaneous over a region of several hundred kilometres, and extends $3^{\circ}$ poleward of the substorm disturbance as defined by the auroral and electron temperature data. The poleward expanding region of aurora and elevated electron temperatures itself is characterised by stronger equatorward line-ofsight velocity, and ion temperature enhancements, indicating an extended region of enhanced precipitation and dynamic electric fields. The most intense ion temperature enhancements are confined to the edge of the poleward expanding structure. The broad region of flow suppression poleward of, and the enhanced flows around the edge of, the substorm-disturbed region are consistent with the disruption and subsequent deflection of the flow around the boundary of the substorm-disturbed region, as observed by Fox et al. (2000). The enhanced precipitation implied by the elevated electron temperatures results in a fourfold increase in the Hall conductance at $68^{\circ}-68.5^{\circ}$ latitude. The conductivity reaches a peak in association with both impulsive changes in the substorm onset region. The region of suppressed electric field is not, however, confined to the region of high conductivity. The high-conductivity region forms an obstacle to the flow, thus creating a region of low-electric field and low conductivity poleward of the main substorm disturbed electrojet. This combination of low conductivity and low-electric field results in the modest magnetic field disturbances observed poleward of the main substorm electrojet by BJN at 2254 in Fig. 3.

The two-dimensional ionospheric convection measurements available from the SuperDARN radars at Hankasalmi and Pykkvibær allow a picture to be built of the effects of these dynamic flow changes on the larger scale nightside convection pattern. This sequence of dynamic flow observations is illustrated schematically in Fig. 10. Before the substorm onset flow is predominantly equatorward. Figures 8 and 9 demonstrate that the dominant effect on the large-scale convection at the moment of substorm onset is the stagnation of flow caused by the highly conducting substorm-disturbed region. This coincides with the commencement of the (a)
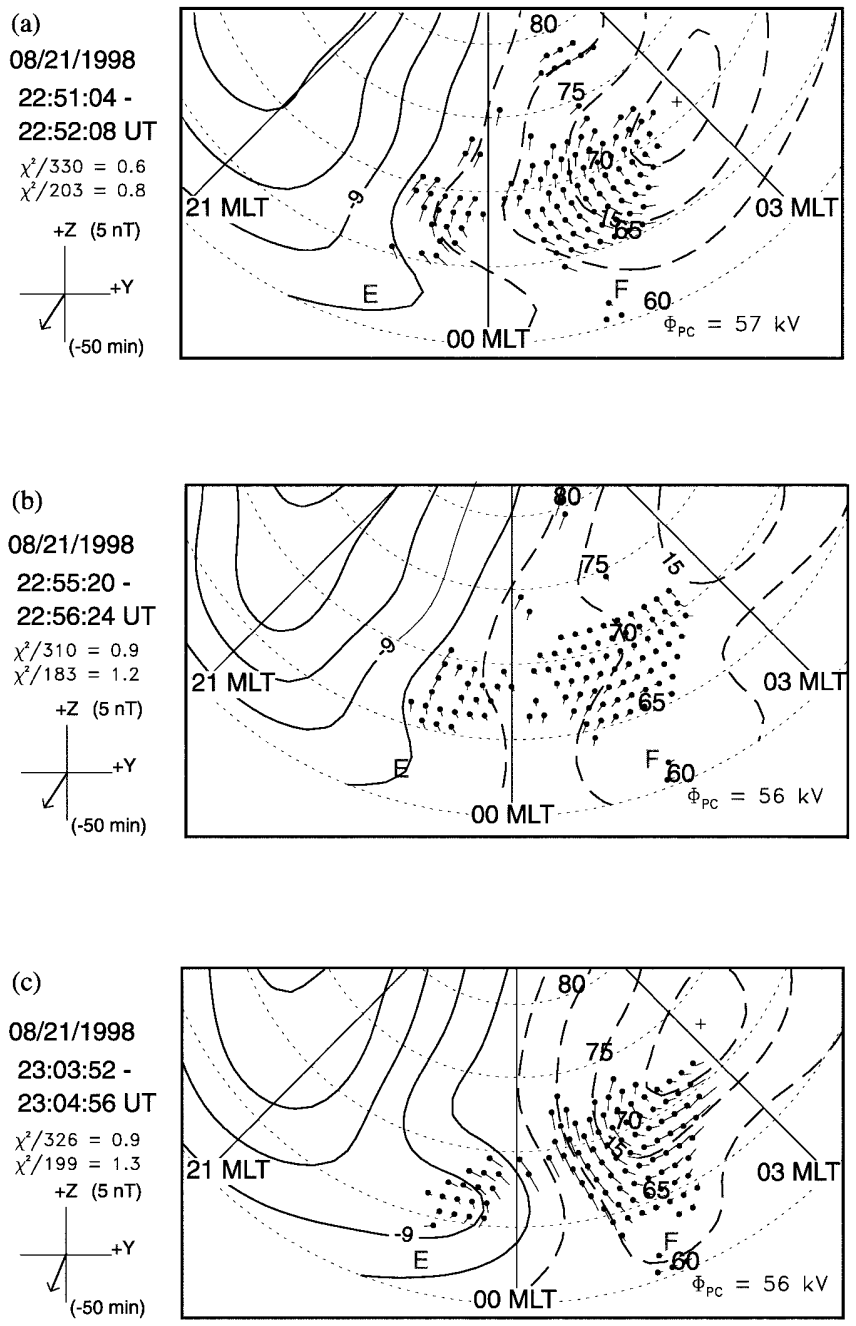

Fig. 9a-c. Flow vectors and equipotential contours for the Northern Hemisphere SuperDARN data presented in magnetic local timemagnetic latitude coordinates. These data are calculated using the potential map technique. The $Y$ and $Z$ components of the IMF, lagged by $50 \mathrm{~min}$, used in the equipotential calculation, are shown next to the appropriate panel (see text for details). Three intervals are examined: 2251:04-2252:08 UT, 2255:20-2256:24 UT and 2303:522304:56 UT

enhanced auroral intensity over a smaller area, and occurs over an area of $\sim 300 \mathrm{~km}$ in latitude and $\sim 600 \mathrm{~km}$ longitude over a time scale of less than $10 \mathrm{~s}$. Two similar instances of flow suppression are observed at 2254 and 2305 UT. Subsequently, over a time scale of a few minutes, flow magnitudes increase as the flows are diverted around the expanding obstacle. At this time the auroral observations can be seen to have expanded rapidly westwards, whilst the ionospheric flows have strengthened considerably. A predominantly eastward flow component is now observed, with equatorward flow in the west and poleward flow in the east. These regions of rapid flow encircle the equatorward edge of a region of low flow in the centre of the Hankasalmi fieldof-view. The flow direction around the region of low flow is likely to be determined by the background flow direction prior to the substorm activity, as suggested by Morelli et al. (1995). 
Behaviour of the ionospheric plasma

flow at substorm onset

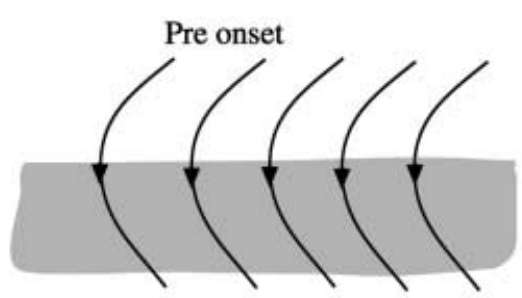

Onset over $10 \mathrm{~s}$

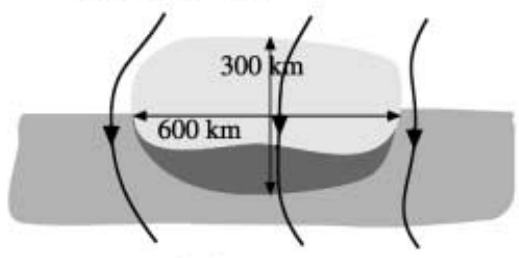

$1 \mathrm{~min}$
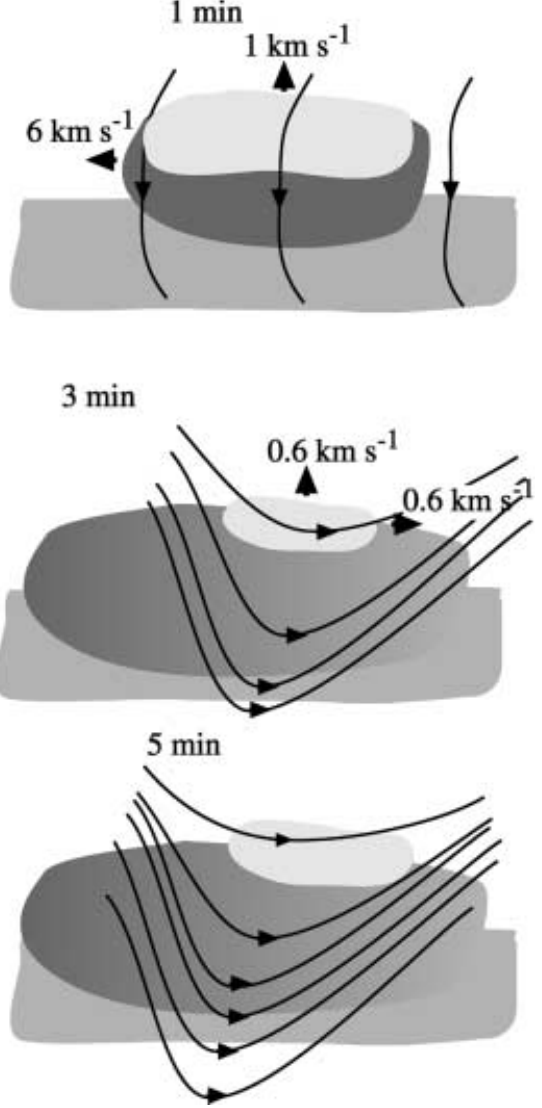

Fig. 10. A schematic of the development of the impulsive electrojets and plasma flows for $5 \mathrm{~min}$ after the substorm expansion phase onset. Arrowed solid lines indicate plasma flow streamlines. Dark shading indicates regions of high ionospheric conductivity in the impulsive and quasi-steady electrojets. Light shading indicates flow suppression in the low conductivity region. Large arrows indicate expansions of these regions

The impulsive changes in the ionospheric electric field occur at the beginnings of the intervals of positive $Y$ component disturbance in the ground magnetic field (Fig. 6). The existence of a $Y$ component magnetic field perturbation implies a significant north-south current flow in addition to the westward electrojet at the eastward edge of the substorm onset region. The positive $Y$ component disturbance implies an equatorward current, and thus presumably corresponds to the relative increase in equatorward current caused by the reduction in equatorward flow measured by the radars. Some positive $Y$ component deflection occurs before the flow suppression at 2305 UT, and may be the signature of the highly dynamic flows which occur between the two flow suppressions. These north-south current systems are transient in nature, and represent substructure within the main substorm current wedge currents. The highly structured ionospheric electric and ground magnetic fields seen here are consistent with the observations of Nakamura et al. (1993), who demonstrated that there were highly structured aurora expanding eastward at the eastern end of the substorm auroral bulge. The existence of considerable north-south currents in this region also demonstrates that there may be larger total currents currents flowing than would be predicted by a simple east-west electrojet model, as suggested by Kamide (1996). Such observations, in addition to being important elements of the ionospheric signature of substorm onset, may provide useful input to future modelling of the substorm process which includes magnetospheric and ionospheric effects (e.g. Kan, 1998).

The poleward expanding electron temperature feature described is essentially the radar signature of the poleward-expanding substorm bulge. It is interesting to compare the poleward motion and extent of this signature with that observed by the Polar UVI instrument. Figure 11 presents a latitude-time-parameter representation of data from Hankasalmi, Polar UVI and the ESR, between 2230 and 2330 UT between $63^{\circ}$ and $76^{\circ}$ magnetic latitude. Figure 11a illustrates the equatorward migration of the HF radar scatter in the growth phase of the substorm, between 2230 and 2250, as discussed earlier in this section and in Sect. 3.1. Flow suppression, and subsequent dynamic flows can be seen after this during the expansion phase. The initial onset of auroral luminosity observed by Polar at 2253 UT in Fig. $11 \mathrm{~b}$ can be seen to coincide, within the time resolution of the UVI instrument, to the rapid stagnation of flow observed by Hankasalmi between $69^{\circ}$ and $72^{\circ}$ (Fig. 11a). Both the UVI data and the ESR electron temperature data subsequently expand poleward (Fig. $11 \mathrm{~b}, \mathrm{c})$. The UVI signature, however, appears to expand only as far as $\sim 70^{\circ}$, whereas the enhanced electron temperatures, presumably resulting from softer precipitation than the required for a significant UVI intensity, expand to $72^{\circ}$. This disparity between the ESR and UVI data is consistent with the statistical offset found between Viking UV images and particle precipitation boundaries derived from $32 \mathrm{eV}-30 \mathrm{keV}$ particles measured by the DMSP spacecraft observed by Kauristie et al. (1999).

\section{Summary}

On August 21st 1998, a sharp southward turning of the IMF, following on from a $20 \mathrm{~h}$ period of northward 


\section{SUPERDARN PARAMETER PLOT}

CUTLASS, Polar UVI, and ESR

21 Aug 1998

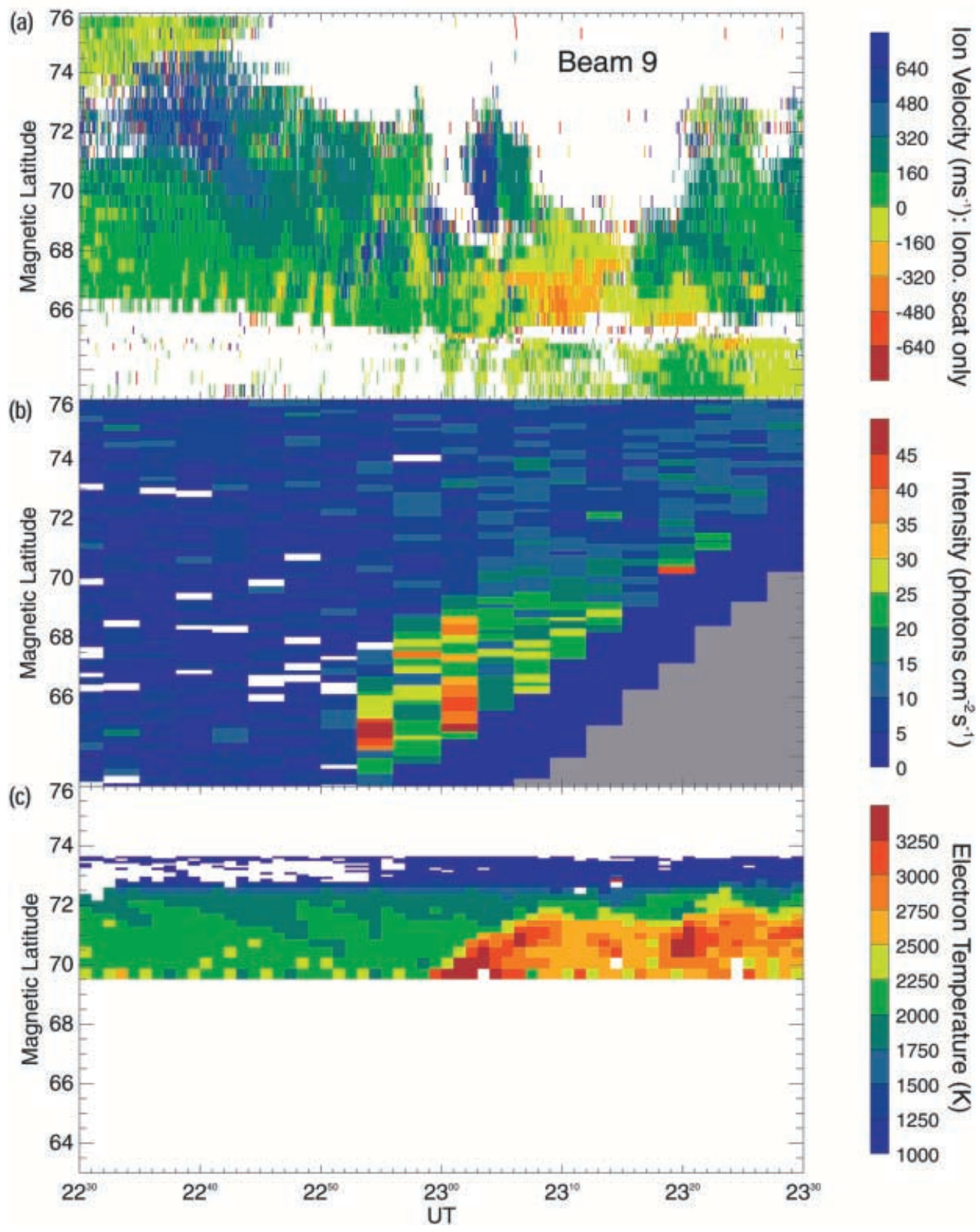

Fig. 11a-c. A latitude-time-parameter representation of data from Hankasalmi, Polar UVI and the ESR, 2230-2330 UT on the 21st August, 1998. a Hankasalmi beam 9 line of sight velocity. Colour coding is as described for Fig. 4. b Polar UVI auroral intensity. c ESR electron temperature

directed magnetic field resulted in an isolated substorm over northern Scandinavia and Svalbard. A combination of high-time resolution and large spatial scale measurements from an array of coherent scatter and incoherent scatter ionospheric radars, ground magnetometers and the Polar UVI imager has allowed the electrodynamics of the impulsive substorm onset region at the expansion phase onset to be studied in great detail. The observations are made at the eastward edge of the expanding electrojet. A number of new features are observed.

The substorm-disturbed electrojet region is characterised by a strong enhancement of the electron temperature and UV aurora. The poleward expanding auroral structure moves initially at $0.9 \mathrm{~km} \mathrm{~s}^{-1}$ poleward, slowing to $0.6 \mathrm{~km} \mathrm{~s}^{-1}$ by $71.5^{\circ}$ latitude. This polewardexpanding auroral feature finally reaches a latitude of $72.5^{\circ}$. The optical signature expands rapidly westwards at $\sim 6 \mathrm{~km} \mathrm{~s}^{-1}$, whilst the eastward edge also expands eastward at $\sim 0.6 \mathrm{~km} \mathrm{~s}^{-1}$. Typical flows of $600 \mathrm{~m} \mathrm{~s}^{-1}$ and conductances of $2 \mathrm{~S}$ were measured before the auroral activation, which rapidly changed to $\sim 100 \mathrm{~m} \mathrm{~s}^{-1}$ and $10-20 \mathrm{~S}$ respectively. These values are consistent with previous measurements with EISCAT and with HF radars, which have suggested that typical values of flow and conductance within the substormdisturbed electrojet are 50-200 $\mathrm{m} \mathrm{s}^{-1}$ and 20-100 S. The initial flow response to the substorm expansion phase onset is a flow suppression. This region of suppressed 
flow is observed up to some $300 \mathrm{~km}$ poleward of the initial region of auroral luminosity, imposed over a time scale of less than $10 \mathrm{~s}$. Thus the high-conductivity region of the electrojet region acts as an obstacle to the flow, resulting in a region of low-electric field, but also low conductivity poleward of the high-conductivity region. Rapid flows are observed at the edge of the highconductivity region, and subsequently the flow enhances, flowing around the expanding auroral feature in a direction determined by the flow pattern prevailing before the substorm intensification. The precipitation region associated with the substorm-disturbed region extended some $2^{\circ}$ further poleward than the UV auroral signature associated with it.

Acknowledgements. The authors thank the director and staff of EISCAT for the operation of the facility and dissemination of the data. EISCAT is an international facility funded collaboratively by the research councils of Finland (SA), France (CNRS), the Federal Republic of Germany (MPG), Japan (NIPR), Norway (NAVF), Sweden (NFR) and the United Kingdom (PPARC). The SuperDARN Hankasalmi and Pykkvibær HF radars are deployed and operated by the University of Leicester, and funded by the PPARC (Grant PPA/R/R/1997/00256), the Finnish Meteorological Institute, and the Swedish Institute for Space Physics. IMAGE data were kindly supplied by the Finnish Meteorological Institute. We would like to thank G. Parks, M. Brittnacher and NASA for the provision of Polar UVI data. We are grateful to Ron Lepping and Keith Ogilvie, principal investigators on the Wind spacecraft MFI and SWE instruments respectively. JAD, SEM, NMW and GP are supported on PPARC Grant PPA/G/O/1997/000254. We would also like to thank Paul Eglitis for the loan of his horsebox.

The Editor-in-chief thanks K. Kauristie for the help in evaluating this paper.

\section{References}

Baker, K. B., and S. Wing, A new magnetic coordinate system for conjugate studies at high latitudes, J. Geophys. Res., 94, 9139, 1989.

Baumjohann, W., R. J. Pellinen, H. J. Opgenoorth, and E. Nielsen, Joint two-dimensional observations of ground magnetic and ionospheric electric fields associated with auroral zone currents: current systems associated with local auroral break-ups, Planet Space Sci., 29, 431, 1981.

Cowley, S. W. H., and M. Lockwood, Excitation and decay of solar wind-driven flows in the magnetosphere-ionosphere system, Ann. Geophysicae, 10, 103, 1992.

Davies, J. A., M. Lester, B. Jenkins, and R. J. Moffett, Dayside ion frictional heating: EISCAT observations and comparison with model results, J. Atmos. Terr. Phys., 57, 775, 1995.

Fox, N. J., S. W. H. Cowley, J. A. Davies, R. A. Greenwald, M. Lester, M. Lockwood, and H. Lühr, Ionospheric ion and electron heating at the poleward boundary of a polewardexpanding substorm-disturbed region, (in Press.) J. Geophys. Res., 2000.

Greenwald, R. A., K. B. Baker, J. R. Dudeney, M. Pinnock, T. B. Jones, E. C. Thomas, J.-P. Villain, J.-C. Cerisier, C. Senior, C. Hanuise, R. D. Hunsucker, G. Sofko, J. Koehler, E. Nielsen, R. Pellinen, A. D. M. Walker, N. Sato, and H. Yamagishi, Darn/Superdarn: a global view of the dynamics of high-latitude convection, Space Sci. Rev., 71, 761, 1995.

Inhester, B., W. Baumjohann, R. A. Greenwald, and E. Nielsen, Joint two-dimensional observations of ground magnetic and ionospheric electric fields associated with auroral zone currents 3. Auroral zone currents during the passage of a westward travelling surge, J. Geophys., 49, 155, 1981.
Kamide, Y., The substorm current system: predicting specific features, Proc. ICS-3, ESA SP-389, p5, 1996.

Kan, J. R., A globally integrated substorm model: tail reconnection and magnetosphere-ionosphere coupling, J. Geophys. Res., 103, $11787,1998$.

Kauristie, K., J. Wegand, T. I. Pulkkinen, J. S., Murphree, and P. T. Newell, Size of the auroral oval: UV and precipitation boundaries compared, J. Geophys. Res., 104, 2321, 1999.

Lepping, R. P. et al., The WIND magnetic field investigation, Space Sci. Rev., 71, 207, 1995.

Lewis, R. V., M. P. Freeman, A. S. Rodger, G. D. Reeves, and D. K. Milling, The electric field response to the growth phase and expansion phase onset of a small isolated substorm, Ann. Geophysicae, 15, 289, 1997.

Lühr, H., The IMAGE magnetometer network, STEP Int. Newsl. 4 (10), 4, 1994.

Lühr, H., A. Aylward, S. C. Buchert, A. Pajunpää, T. Holmboe, and S. M. Zalewski, Westward moving dynamic substorm features observed with the IMAGE magnetometer network and other ground-based instruments, Ann. Geophysicae, 16, 425, 1998.

Milan, S. E., J. A. Davies, and M. Lester, Coherent HF radar backscatter characteristics associated with auroral forms identified by incoherent radar techniques: a comparison of CUTLASS and EISCAT observations, J. Geophys. Res., 104, 22 591, 1999.

Morelli, J. P., R. J. Bunting, S. W. H. Cowley, C. J. Farrugia, M. P. Freeman, E. Friis-Christensen, G. O. L. Jones, M. Lester, R. V. Lewis, H. Lühr, D. Orr, M. Pinnock, G. D. Reeves, P. J. S. Williams, and T. K. Yeoman, Radar observations of auroral zone flows during a multiple-onset substorm, Ann. Geophysicae, 13, 1144, 1995.

Nakamura, R., T. Oguti, T. Yamamoto, and S. Kokubun, Equatorward and poleward expansion of the auroras during auroral substorms, J. Geophys. Res., 98, 5743, 1993.

Olsson, A., M. A. L. Persson, H. J. Opgenoorth, and S. Kirkwood, Particle precipitation in auroral breakups and westward travelling surges, J. Geophys. Res., 101, 24 661, 1996.

Opgenoorth, H. J., R. J. Pellinen, W. Baumjohann, E. Nielsen, G. Marklund, and L. Eliasson, Three dimensional current flow and particle precipitation in a westward travelling surge (observed during the Barium-GEOS rocket experiment), J. Geophys. Res., 88, 3138, 1983.

Opgenoorth, H. J., B. Bromage, D. Fontaine, C. LaHoz, A. Huuskonen, H. Kohl, U.-P. Løvhaug, G. Wannberg, G. Gustaffson, J. S. Murphree, L. Eliasson, G. Marklund, T. A. Potemra, S. Kirkwood, E. Nielsen, and J.-E. Wahlund, Coordinated observations with EISCAT and the Viking satellite: the decay of a westward travelling surge, Ann. Geophysicae, 7, 479, 1989.

Persson, M. A. L., A. T. Aikio, and H. J. Opgenoorth, Satelliteground coordination: late growth and Early expansion phase of a substorm, in, Proc. ICS-2, Eds. J. R. Kan, J. D. Craven, and S.-I. Akasofu, Fairbanks, USA, 1994.

Rishbeth, H., and P. J. S. Williams, The EISCAT ionospheric radar: the system and its early results, Q. J. R. Astr. Soc., 26, 478, 1985.

Ruohoniemi, J. M., and K. B. Baker, Large-scale imaging of highlatitude convection with Super Dual Auroral Radar Network HF radar observations, J. Geophys. Res., 103, 20 797, 1998.

Ruohoniemi, J. M., and R. A. Greenwald, Statistical patterns of high-latitude convection obtained from Goose Bay HF radar observations, J. Geophys. Res., 101, 21 743, 1996.

Ruohoniemi, J. M., R. A. Greenwald, K. B. Baker, J.-P. Villain, C. Hanuise, and J. Kelly, Mapping high-latitude plasma convection with coherent HF radars, J. Geophys. Res., 94, 13 463, 1989.

Samson, J. C., Mapping substorm intensifications from the ionosphere to the magnetosphere, in, Proc. ICS-2, Eds. J. R. Kan, J. D. Craven, and S.-I. Akasofu, Fairbanks, USA, 1994.

Samson, J. C., D. D. Wallis, T. J. Hughes, F. Creutzberg, J. M. Ruohoniemi, and R. A. Greenwald, Substorm intensifications 
and field line resonances in the nightside magnetosphere, J. Geophys. Res., 97, 8495, 1992.

Shand, B. A., T. K. Yeoman, R. V. Lewis, R. A. Greenwald, and M. R. Hairston, Inter-hemispheric contrasts in the ionospheric convection response to changes in the interplanetary magnetic field and substorm activity: a case study, Ann. Geophysicae, 16, 764, 1998.

Torr, M. R., D. G. Torr, M. Zukic, R. B. Johnson, J. Ajello, P. Banks, K. Clark, K. Cole, C. Keffer, G. Parks, B. Tsurutani, and J. Spann, A far ultraviolet imager for the international solar-terrestrial physics mission, Space Sci. Rev., 71, 329, 1995.

Untiedt, J., and W. Baumjohann, Studies of polar current systems using the IMS Scandinavian magnetometer array, Space Sci. Rev., 63, 245, 1993.

Villain, J.-P., J. M. Ruohoniemi, R. A. Greenwald, and K. B. Baker, HF radar observations of $\mathrm{E}$ region plasma irregularities produced by oblique plasma streaming, J. Geophys. Res., 92, $12327,1987$.
Wannberg G., L. Wolf, L.-G. Vanhainen, K. Koskenniemi, J. Röttger, M. Postila, J. Markkanen, R. Jacobsen, A. Stenberg, R. Larsen, S. Eliassen, S. Heck and A. Huuskonen, The EISCAT Svalbard radar: a case study in modern incoherent scatter radar system design, Radio Sci., 32, 2283, 1997.

Williams, P. J.S., and A. R. Jain, Observations of the high-latitude trough using EISCAT, J. Atmos. Terr. Phys., 48, 423, 1986.

Yeoman, T. K., and H. Lühr, CUTLASS/IMAGE observations of high latitude convection features during substorms, Ann. Geophysicae, 15, 692, 1997.

Yeoman, T. K., H. Lühr, R. W. H. Friedel, S. Coles, M. Grandé, C. H. Perry, M. Lester, P. N. Smith, H. J. Singer, and D. Orr, CRRES/ground-based multi-instrument observations of an interval of substorm activity, Ann. Geophysicae, 12, 1174, 1994.

Yeoman, T. K., T. Mukai, and T. Yamamoto, Simultaneous ionospheric and magnetospheric observations of azimuthally propagating transient features during Substorms, Ann. Geophysicae, 16, 754, 1998. 